$\begin{array}{ll} & \text { Etnográfica } \\ \text { etnográfica } & \text { Revista do Centro em Rede de Investigação em }\end{array}$

Antropologia

vol. 15 (3) | 2011

Vol. $15(3)$

\title{
Juventudes e contemporaneidade: entre a autonomia e a tutela
}

Contemporaneity and youth: between autonomy and protection

\section{Ana Paula Serrata Malfitano}

\section{(2) OpenEdition}

Journals

Edição electrónica

URL: https://journals.openedition.org/etnografica/1060

DOI: 10.4000/etnografica. 1060

ISSN: 2182-2891

\section{Editora}

Centro em Rede de Investigação em Antropologia

Edição impressa

Data de publição: 1 outubro 2011

Paginação: 523-542

ISSN: 0873-6561

\section{Refêrencia eletrónica}

Ana Paula Serrata Malfitano, «Juventudes e contemporaneidade: entre a autonomia e a tutela»,

Etnográfica [Online], vol. 15 (3) | 2011, posto online no dia 23 outubro 2011, consultado o 11 fevereiro 2022. URL: http://journals.openedition.org/etnografica/1060 ; DOI: https://doi.org/10.4000/ etnografica. 1060

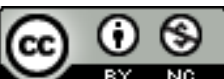

Etnográfica is licensed under a Creative Commons Attribution-NonCommercial 4.0 International License. 


\title{
Juventudes e contemporaneidade: entre a autonomia e a tutela
}

\section{Ana Paula Serrata Malfitano}

\begin{abstract}
A juventude vem ganhando discussões e ações públicas mundiais em proporções ascendentes, caracterizada como um grupo social plural e emergente. Contudo, a partir de uma visão homogeneizante, os jovens são predominantemente interpretados como um "problema político" que requer o desenvolvimento de intervenções disciplinares e de controle. Tais intervenções debatem-se com a constituição jurídica, cultural e social da juventude, questionando quem deve estar em proteção, sob tutela, e quem tem a liberdade e a autonomia de decisão sobre si. Os serviços sociais direcionados a essa população intencionam realizar seu cuidado com vistas à promoção de sua autonomia. A partir de um trabalho de campo de base etnográfica, realizado por quatro anos junto a instituições sociais e a jovens que as frequentavam, apresenta-se a trajetória de vida de um jovem no limiar de entrada para a vida adulta, compreendendo a passagem para a maioridade como um evento crítico de sofrimento social. Enfatiza-se o acesso, naquela história, a uma autonomia socioeconômica, mas que se apresenta como exceção, devido ao pequeno alcance concreto das ações dos serviços sociais junto aos jovens de grupos populares.
\end{abstract}

PALAVRAS-CHAVE: juventude, autonomia, tutela, instituições sociais.

\section{A TEMÁTICA DA JUVENTUDE VEM GANHANDO O CENÁRIO PÚBLICO DE debate por diversas vertentes. ${ }^{1}$ Perpassa a discussão acerca dos cursos de vida e seus ritos de passagem, das mudanças na concepção de juventude como valor sociocultural, enfatizando que, na contemporaneidade, acompanha-se uma busca contínua pela permanência no estado juvenil, e não pela sua vivência}

l Parte das reflexões aqui apresentadas compõe a tese de doutorado A Tessitura da Rede, entre Pontos e Espaços: Políticas e Programas Sociais de Atenção à Juventude - A Situação de Rua em Campinas, SP”, defendida na Faculdade de Saúde Pública da Universidade de São Paulo, Brasil, e orientada pelo prof. doutor Rubens de Camargo Ferreira Adorno. Este trabalho contou com o apoio da Capes (Coordenadoria de Aperfeiçoamento de Pessoal de Nível Superior, Brasil). 
como etapa de transição, a partir de uma configuração de dissolução da vida adulta (Featherstone 1994; Debert 2010).

No arcabouço investigatório sobre quem é o jovem na sociedade contemporânea insere-se a multiplicidade de juventudes, que pode ser tratada sob as perspectivas social, cultural, política, econômica e outras (Abramo e León 2005). Porém, há uma demarcação fundamental sempre presente, assinalada aqui como necessária para a discussão: a classe social a que o indivíduo pertence. A estrutura socioeconômica capitalista da sociedade ocidental define uma importante vertente de análise que também cria diferenças nas possibilidades de vivência das juventudes. $\mathrm{O}$ acesso aos direitos sociais - como educação, cultura, saúde e outros -, aos bens materiais e à possibilidade de inserção no mundo do trabalho são elementos relevantes para se refletir sobre quem é o jovem e quais as perspectivas e possibilidades nesse estágio de liminaridade e transição para a vida adulta. As diferenças entre as juventudes passam, também, pelas classes sociais, pela desigualdade socioeconômica, pelo acesso aos direitos, pela diferenciação cultural de alguns grupos, dentre outros muitos elementos. Pertencer a uma classe desfavorecida economicamente determina, mesmo que não totalmente, as possibilidades de inserção dos jovens na sociedade.

Assim, opta-se, no presente trabalho, pelo enfoque nos jovens de grupos populares urbanos, enfatizando a presença da relacionada discussão entre sociabilidade, acessos, desigualdades e direitos. Demarca-se o conceito de sociabilidade enquanto construção do próprio social a partir da interação dos sujeitos, definindo e redefinindo simbolicamente as diferenças socioculturais (Frúgoli Jr. 2007).

Entre os espaços de sociabilidade juvenil, discute-se aqui o papel das instituições sociais e sua intervenção sobre os jovens, na sua proposição de promoção de ações para o cuidado e a tutela dessa população, visando sua autonomia para a entrada na vida adulta. Partindo da compreensão da entrada na vida adulta dos jovens de grupos populares como um evento crítico de sofrimento social, conforme os conceitos de Kleinman, Das e Lock (1997), problematizam-se os alcances institucionais para a autonomia de tais jovens.

Para tanto, parte-se de um trabalho de base etnográfica, para o qual lançamos mão de análises de quatro anos de terreno em serviços sociais direcionados a adolescentes em situação de rua, em um município brasileiro de grande porte. Tendo como base nossa convivência com os jovens e com os profissionais da rede de serviços socais, assim como os registros formais das instituições, apresentamos parte da trajetória de Lucas, que alcançou sua autonomia financeira após completar 18 anos, a partir da intervenção das instituições sociais. Porém, sua trajetória pode ser interpretada como uma exceção, dado o pouco alcance das ações efetivas promovidas pelas instituições sociais para a autonomia dessa população, permanecendo, “apenas", no escopo da tutela. 


\section{JUVENTUDE E “PROBLEMA POLÍTICO”}

Os grupos juvenis têm sido caracterizados como plurais e emergentes nas diferentes definições e concepções teóricas que os cercam (Abramo e León 2005; IARD 2001). Entretanto, em contraposição ao discurso apresentado, observa-se uma uniformização da ideia de juventude, considerando-a indistintamente como um grupo único, para o qual se lança o olhar como "problema político" necessitando de intervenção e de "controle". Percebe-se tal fato pela crescente preocupação e investimento internacionais verificados nos últimos quinze anos, os quais buscam ofertar resposta às demandas sociais expressas sob a forma da necessidade de intervenções assistenciais junto a essa população, seja para a promoção de seu cuidado e proteção, seja para a tentativa de controle da transgressão e da infração.

A construção do imaginário acerca das necessidades juvenis e sua inserção na agenda política internacional, com ações implementadas pelos Estados e por organizações não governamentais de âmbitos nacionais e internacional, perpassa a "crise" contemporânea, acarretada pelas transformações no mundo do trabalho, pelas novas formas de pobreza e de marginalidade (Attias-Donfut 1996), assim como pela associação superficial entre violência e juventude. Contudo, as discussões acerca das dimensões político-econômica e social que calcam a demanda juvenil contemporânea ganham pouca visibilidade, prevalecendo o argumento da intervenção para o "controle" da violência. Este fato é influenciado pela expressiva veiculação pela mídia de notícias relacionadas a comportamentos violentos por parte de adolescentes e jovens (Sposito 2007) por exemplo, os episódios de manifestação popular com expressiva participação da população juvenil ocorridos na periferia (banlieu) francesa, pela discussão da situação social da nova geração de imigrantes, notadamente na Europa.

No caso francês, os jovens são, a partir dos anos de 1970, compreendidos como as principais vítimas do desemprego europeu, sendo que as mobilizações e manifestações são resultados sociais que demonstram a necessidade de intervenção em tal questão (Dubet 1987). Entretanto, anos depois aparece a ênfase da discussão pública das mobilizações nos episódios de violência e nas questões urbanas, articulados aos bairros de moradia de imigrantes, esvaziando o discurso político acerca das manifestações e do desemprego, e restando o imaginário e a associação entre a violência e a população jovem (Loncle 2003).

Bourdieu (1986) considera que o "problema da juventude" se instala quando há a crise no mundo do trabalho e novas desigualdades estabelecidas. Assim, constrói-se a visão uniforme e globalizada da juventude como "problema político", instalado na esfera pública e que interfere na dinâmica social (Abad 2003). Porém, é preciso assinalar que se trata de uma visão direcionada aos jovens de grupos populares, na invisibilidade de sua multiplicidade sociocultural e na compreensão pasteurizada da necessidade de seu controle para a ordem. 
Portanto, um marco para a discussão da juventude centra-se na crise da sociedade salarial, descrita por Castel (1998). O autor define-a pela diminuição gradativa de postos de trabalho assalariados levando a dificuldades, que perpassam as classes sociais, na entrada e manutenção na esfera do trabalho para todos, mas, em especial, para os jovens. Com isso, há uma tendência transversal de prolongamento da juventude para que esses indivíduos tendam a retardar sua entrada no mercado. Esse processo é percebido, de maneira mais evidente, nas classes média e alta, nas quais os jovens têm passado por um processo de escolarização formal aumentado, ampliando, também, o tempo de dependência econômica de seus pais (IARD 2001). Nos segmentos populares, a necessidade e o imaginário em torno do trabalho permanecem e fortalecem-se apesar desses elementos, culminando em uma maior contradição para os jovens na dificuldade de acesso ao trabalho:

"Por um lado, muitos jovens de classes populares gozam de abundante tempo livre, embora se trate de um tempo de espera, vazio, em virtude da falta de trabalho, de estudo e de alternativas de um ócio criativo e vitalmente enriquecedor. [...] o tempo da angústia e da impotência, o tempo da estigmatização social, um tempo que empurra na direção da marginalidade e da exclusão, o tempo do ficar 'marcando bobeira' numa esquina, exposto aos agentes de limpeza social. [...] por outro lado, nos jovens de classes sociais com possibilidade de uma postergação legitimada das responsabilidades adultas, o período de formação tende cada vez mais a alongar-se, seja pela complexidade dos conhecimentos exigidos para uma inserção profissional de acordo com as expectativas da classe, seja pela falta de um destino econômico assegurado pela educação" (Abad 2003: 26).

Todavia, partindo desse cenário, no qual a intervenção política é demandada para criar respostas, observa-se que tais ações podem reproduzir a ideologia dominante ou, em contraposição, "contemplar configurações inovadoras que compõem o campo de forças e de disputas que constituem o jovem como categoria social no interior dos espaços públicos da sociedade" (Sposito 2007: 6).

Para a compreensão das disputas e dinâmicas estabelecidas, que também passam pelas instituições sociais e suas práticas implementadas, faz-se necessário lançar um olhar às múltiplas juventudes e suas formas de apreensão, abordagem e intervenção. Abramo e León (2005) propõem um olhar acerca das gerações e classes de idade, dos estilos de vida juvenil, dos ritos de passagem infanto/adolescente/juvenil, assim como das trajetórias de vida e novas condições juvenis.

Do ponto de vista cultural, Featherstone (1994: 62) aborda as "invenções" de fases e delimitações nos cursos da vida, destacando que nas sociedades modernas - "com base nos processos de industrialização, urbanização e 
administração pública das populações [...] - uma série de idades compulsórias foram instituídas para começar a deixar a escola, assim como para ingressar no trabalho, casar, votar, se aposentar, etc.", resultando em "uma maior padronização e ordenação do curso da vida". Acrescentam-se aos aspectos econômicos as mudanças culturais e sua retroalimentação, trazendo, atualmente, o debate sobre as modificações, diferenciações, prolongamentos e novas demandas em torno da juventude. Tais fatores ganham complexidade em um contexto sociocultural contemporâneo de constantes e rápidas mudanças em que a sociabilidade, valores e modos de vida enquadram-se e diversificam-se em uma sociedade moderna, liberal, pós-contemporânea ou reflexiva, conforme as nomenclaturas aplicadas nesse campo por alguns teóricos.

Circunscrevemos nossa vertente de análise nas trajetórias de vida e novas condições juvenis, as quais são constituídas de forma não linear, criando percursos diversos que podem ser nomeados, segundo Pais (2005), de trajetórias "ioiô", na medida em que não têm previsibilidade e criam ciclos de idas e vindas entre as possibilidades de criação de vida pelos meninos e meninas.

Buscamos, no relato etnográfico sobre a trajetória pessoal, possibilidades de compreensão do cenário macrossocial da juventude e das ações a ela direcionadas, com destaque para o sofrimento social vivenciado.

Enfocamos a questão na passagem para a vida adulta, por meio da trajetória de vida de Lucas, tendo como ponto de análise as ações institucionais direcionadas a ele e as possibilidades de ascensão à autonomia, que envolvem aspectos socioculturais e também desdobramentos nas especificações normativas, como, por exemplo, no escopo jurídico.

\section{PRINCÍPIO JURÍDICO: O APARATO PARA CRIANÇAS E ADOLESCENTES NA SOCIEDADE BRASILEIRA}

A constituição do aparato jurídico brasileiro contemporâneo de atenção às crianças e aos adolescentes efetivou-se por ações políticas realizadas pelos movimentos sociais pelos direitos da infância e da adolescência, aliados aos movimentos pela democratização do Brasil, na década de 1980, que estavam juntos na luta pelo fim da ditadura no país. Como uma das consequências desse momento histórico, a Constituição Brasileira (Brasil 1988) declara a criança e o adolescente como "absoluta prioridade" ( art. $^{\circ} 227 .^{\circ}$ ), inaugurando o reconhecimento do princípio jurídico brasileiro na atenção a essa população, que se apresenta consoante com declarações internacionais, como a Declaração de Genebra sobre os Direitos da Criança (1924) e a Declaração Universal dos Direitos da Criança (1959), revista e ampliada na Convenção da Organização das Nações Unidas sobre os Direitos da Criança (1989).

Em continuidade com esse movimento, em 1990 há a promulgação do Estatuto da Criança e do Adolescente (ECA), o qual busca uma universalidade 
para os direitos e intervenções com todas as crianças e adolescentes brasileiros. O ECA (Brasil 1990) estabelece os direitos básicos para todos, "proteção integral à criança e ao adolescente" (art. $\left..^{\circ} 1 .^{\circ}\right)$, definindo criança como a pessoa com "até 12 anos de idade incompletos, e adolescente aquela entre 12 e 18 anos de idade" (art. $\left.{ }^{\circ} 2^{\circ}\right)$. A partir deste, delega: "É dever da família, da comunidade, da sociedade em geral e do poder público assegurar, com absoluta prioridade, a efetivação dos direitos referentes à vida, à saúde, à alimentação, à educação, ao esporte, ao lazer, à profissionalização, à cultura, à dignidade, ao respeito, à liberdade e à convivência familiar e comunitária" $\left(\right.$ art. $\left.^{\circ} 4 .^{\circ}\right)$, reconhecendo uma "condição peculiar da criança e do adolescente como pessoas em desenvolvimento" (art. $\left.{ }^{\circ}{ }^{6} .^{\circ}\right)$.

A Constituição Brasileira e o ECA determinam, no plano formal, a priorização desse grupo etário no âmbito da política social nacional, devendo ser garantido orçamento para a realização de uma série de serviços pela lei estabelecidos, que visem à promoção do acesso aos direitos básicos, elencados para todos, assim como uma estrutura de suporte para aqueles que não tenham acesso a alguns direitos por meio da família ou da sociedade - como casos de ausência da família - e, ainda, um sistema de reeducação para aqueles que entram em conflito com a lei, por causa de delitos. Em outras palavras, o aparato legislativo brasileiro reconhece a infância e a adolescência como temática prioritária de investimento pelas políticas sociais, sob uma perspectiva universalista, e estabelece a necessidade de criação de serviços, a serem efetuados pelo Estado e pela sociedade (Brasil 1990), que assegurem a autonomia desses sujeitos para a vivência da idade adulta, compreendida, juridicamente, a partir dos 18 anos.

A junção de aspectos econômicos, políticos e culturais consolidou, no plano teórico, "altos ideais para uma sociedade ideal" (Fonseca e Cardarello 1999: 84), como aqueles estabelecidos nos princípios jurídicos brasileiros para a atenção à infância e à adolescência que, todavia, manifestam um grande distanciamento da realidade vivenciada, considerando que é necessário admitir "que os direitos humanos em sua forma abstrata e descontextualizada pouco significam" (1999: 85).

Vale destacar que os avanços teóricos formais jurídicos, acima apresentados, concernem ao universo de crianças e adolescentes, mas não alcançam a juventude. Embora haja referências a esse grupo e também exista uma fase de idade congruente entre adolescência e juventude, segundo algumas divisões etárias, trata-se de categorias diferentes, com problemáticas e demandas diferenciadas, e que, portanto, requerem ações públicas diversas. O ECA caracteriza a criança e o adolescente segundo a faixa etária, porém não aborda a juventude. Existe, portanto, um legado de proteção instituído para a infância no Brasil, alguns apontamentos para a adolescência, porém nenhum aprofundamento jurídico sobre a juventude. Essa mistura de termos estabelecida cria uma confusão de 
interpretações e compreensões, além da invisibilidade da ausência de ações realizadas com a juventude. Pode-se dizer que, "se tomadas exclusivamente pela idade cronológica e pelos limites da maioridade legal, parte das políticas acaba por excluir um amplo conjunto de indivíduos que atinge a maioridade, mas permanecem no campo possível de ações, pois ainda vivem efetivamente a condição juvenil" (Sposito e Carrano 2003: 19).

Nesse debate, em 2004, foi criada pelo governo federal brasileiro uma comissão interministerial, no poder executivo, que apresentou à Câmara dos Deputados um projeto de lei que cria o Plano Nacional de Juventude, que aguarda aprovação, o Estatuto dos Direitos da Juventude e a Proposta de Emenda Constitucional, que incluiu o termo "juventude" na Constituição Brasileira, integrando o texto já existente sobre proteção às crianças e aos adolescentes. Em 2005 foram criados também a Secretaria Nacional da Juventude e o Conselho Nacional da Juventude (Novaes et al. 2006). Em 2010 foi acrescida ao art. $^{\circ} 227 .^{\circ}$ da Constituição Brasileira a priorização das ações com jovens, além das crianças e adolescentes, já referidos no texto original. Reconhece-se uma nova categoria jurídica em debate com a realidade sociocultural (Paula 2010).

Todavia, permanece a definição jurídica de entrada na vida adulta aos 18 anos, e é ela que conjuga o debate sociocultural sobre a (im)possibilidade de muitas juventudes alcançarem a autonomia para o exercício de sua vida, tanto na perspectiva econômica quanto subjetiva. Portanto, apesar da precisa definição legislativa, permanece o relevante debate entre a autonomia e a tutela e, especificamente, sobre as possibilidades e impossibilidades de os serviços sociais realizarem ações que promovam a tutela com a finalidade de facilitar a autonomia aos 18 anos.

\section{JUVENTUDE: O DEBATE ENTRE A AUTONOMIA E A TUTELA}

As ações sociais destinadas a crianças e adolescentes têm, no Brasil, um escopo de proteção e tutela, de acordo com os pressupostos jurídicos acima apresentados. A juventude inaugura-se então neste cenário, assumindo o lugar daquele que também precisa ser protegido e ter garantido o acesso a seus direitos. Entretanto, traz consigo o debate sobre a autonomia e as possibilidades das ações sociais junto a essa população.

Essa polêmica perpassa a compreensão sobre quem deve estar em proteção, sob tutela, e quem tem a liberdade e a autonomia de decisão sobre si. Os serviços sociais são direcionados para uma parte da população compreendida como estando em situação especial de desenvolvimento, e a partir dos 18 anos haveria, supostamente, outros recursos internos e externos para a autonomia, para a vida.

Historicamente viveu-se, primordialmente, o modelo compulsório nas ações públicas voltadas para as crianças e adolescentes populares, pelas quais essa 
população seria educada moralmente, de acordo com o projeto de nação da elite brasileira (Rizzini 2008). Em contraponto, quando se criam intervenções pautadas na desinstitucionalização, na autonomia e na liberdade de escolha, modifica-se um legado instaurado e diversificam-se as possibilidades de intervenção com esse público.

Nessa discussão sobre a maioridade e as vivências sociais dos cursos da vida, as categorias infância, adolescência e juventude misturam-se e ora se distinguem totalmente, ora representam o mesmo grupo. Contudo, é necessário demarcar a diferenciação entre infância e adolescência, assim como as diferentes etapas no interior da adolescência, pois a homogeneização de "crianças e adolescentes" retira a ênfase da necessária proteção das condições infantis. Quando se trata de adolescentes, é preciso distinguir as características de um adolescente de 12 e outro de 17 anos na prática de seus atos, na liberdade sobre si mesmo e na autonomia e responsabilização pelas suas escolhas. As questões sociais contemporâneas interpõem novos modos de vida que criam modificações no que é compreendido e exercido como autonomia no contexto social.

Essas questões não têm um posicionamento único, pela diversidade de vivências de infância, adolescência e juventude que são socialmente constituídas.

Adorno, Alvarenga e Vasconcellos (2005: 17-18) defendem que o conceito de adolescência foi introduzido no universo médico para referir um período de transição, "desprovido de identidade e de vida própria, mas considerado como fase de latência, a exemplo dos processos biológicos de maturação". Argumentam acerca da crítica às ações normativas dirigidas a essa população e conceituam:

"Opondo-se ao conceito de adolescência, a Sociologia trabalha com o conceito de juventude como representativo do caráter que as novas gerações trazem à sociedade, não a encarando, assim, como uma fase de transição para uma idade ou identidade adulta, mas justamente como um campo de inovação, de geração de novas identidades, de discussão de papéis e questionamento do caráter conservador das instituições, dos valores e das normas sociais" (2005: 18).

A indistinção entre adolescência e juventude, ou ainda a substituição do termo "adolescente" por "jovem", não contribui para o debate sobre as diferenciações entre esses cursos e suas necessidades e características singulares que, em alguns momentos, são congruentes; mas, de maneira geral, eles representam grupos distintos com compreensões e definições diversas.

No entanto, nenhuma das práticas estremadas, das mais conservadoras às mais progressistas, enfrentou realmente a questão da autonomia e da proteção. Permanece a difícil tarefa de mediação e debate em torno desse tema. 
Afinal, a que se refere a minoridade? Na esfera pública brasileira, segundo o referencial jurídico, a minoridade se encerra aos 17 anos e 11 meses, ou seja, o jovem que completa 18 anos é considerado adulto e exposto às normas condizentes com esta faixa etária.

Especificamente com relação aos serviços sociais, como aqueles das áreas da saúde e da assistência social, o atendimento, na maior parte dos casos, refere-se à população adolescente, até os 18 anos, ou adulta, após os 18 anos, havendo nessa fase, portanto, uma necessária ruptura de referenciais para aqueles que estão nos equipamentos sociais.

Os meninos e meninas de grupos populares dialogam sobre essa passagem de fases, sendo um assunto comum entre os jovens em torno dos 18 anos, abordando a entrada na vida adulta pela impossibilidade de continuarem como usuários de determinados serviços sociais que frequentavam, assim como pelo temor do sistema judiciário "comum". ${ }^{2}$

Acompanhamos um jovem que completou 18 anos e havia sido usuário de um serviço de saúde por três anos. Após seu aniversário, não ultrapassava mais a porta do local ao qual se dirigia diariamente até então, mesmo que fosse até o serviço constantemente e ficasse do lado de fora solicitando, a partir da porta, para falar com pessoas que conhecia. Não havia nenhuma restrição para a sua entrada, formal ou informalmente estabelecida, e havia mesmo o convite para que ingressasse no local; contudo, sabia da sua perda de condição de usuário daquele local e delimitava suas possibilidades de tutela por aquele universo institucional por meio da porta de entrada, não mais cruzada após sua passagem à vida adulta.

O outro marco de passagem para a vida adulta dava-se pela possibilidade efetiva de encaminhamento aos presídios, "novo serviço" que acessariam caso fossem apreendidos pela prática de atos infracionais. Esse "temor" relacionado à prisão confirmava-se por algumas trajetórias, relatadas por jovens que, com 18 anos recém-completos, eram encaminhados para presídios, quando apreendidos em flagrante, na maioria dos casos por furtos, uso ou tráfico de drogas.

Vemos, nesses casos, a explicitação da influência do fator externo à vida cotidiana daqueles meninos, no caso a legislação da área da infância e da adolescência, como elemento causador de sofrimento social na passagem para a maioridade, marcada pela posição de classe socioeconômica dessa população. Passar a fronteira dos 18 anos implica, pelas questões legislativas componentes do nível macroestrutural, a perda de acessos a serviços sociais que eram até

2 Para a justiça brasileira, os adolescentes, se apreendidos cometendo uma infração, são encaminhados para um serviço jurídico especial voltado ao atendimento de crianças e adolescentes. Após os 18 anos são encaminhados à justiça "comum". Esse fato é do conhecimento dos jovens e entendido como uma mudança concreta que testemunha a passagem para a vida adulta. 
então referências em suas vidas, bem como o medo de entrada na prisão, espaço desconhecido e causador de sofrimento pela possibilidade de aproximação e entrada. Trata-se, conforme descrito por Kleinman, Das e Lock (1997), de um evento crítico fortemente influente no nível local, na vida daqueles meninos e meninas que passam a ser adultos, na medida em que ressignifica o cotidiano de determinado grupo populacional a partir de sua existência jurídica e, com isso, causando sofrimento social em determinadas histórias de vida.

Exemplo do quadro descrito ocorreu com uma jovem que, quando nas ruas, levantava a suspeita de apresentar um rebaixamento intelectual, além de fazer uso intensivo de substâncias psicoativas. Ela foi apreendida, com 18 anos, participando de um furto e encaminhada para um presídio feminino na região onde morava. Quando duas técnicas de um serviço que ela frequentava, ainda adolescente, souberam da ocorrência, foram visitá-la e encontraram-na extremamente medicada. Os funcionários do presídio informaram que ela havia sofrido uma "crise nervosa", com muita agitação, e que fora encaminhada para o serviço de psiquiatria que atende os internos, recebendo essa conduta médica. Observa-se, conforme apontado por Biehl (2008), uma "farmaceutização" das questões de saúde mental da população de baixa renda, nesse caso, especificamente, no contexto prisional. As profissionais, embora não tivessem responsabilidade técnica "pelo caso", procuraram a Justiça e solicitaram, formalmente, a liberação da jovem, que ainda não havia sido reclamada por ninguém de sua família. Quando discutiram junto à promotoria a possibilidade de atestarem seu rebaixamento intelectual e a inadequação da intervenção medicamentosa recebida no presídio, foram aconselhadas a não tomarem essa conduta, que abriria a discussão do encaminhamento da jovem para o serviço de saúde mental judiciário e, assim, a possibilidade de sua liberação seria muito menor, uma vez que dependeria da avaliação médica e, nas condições em que se encontrava de ré primária e acusada de crime de baixa periculosidade, a liberação para responder ao processo em liberdade era quase certa. $\mathrm{O}$ aconselhamento formal jurídico recebido demonstrava o lugar dessa população, também na condição de adultos, e o uso da "loucura", e das doenças que a tangenciam, como penalidade. Pela solicitação apresentada, a jovem foi liberada para responder ao processo em liberdade. Não se soube para onde foi nem com que meios. Outros jovens relataram, tempos depois, que haviam se encontrado com ela novamente nas ruas e sob o uso de drogas.

Wacquant discute a política dos presídios como um recurso de controle dos pobres, chamando-os de "prisões da miséria", argumentando que para as classes trabalhadoras não há atualmente proposição efetiva de acesso a bens sociais, mas sim ações denominadas de políticas sociais que se caracterizam por um caráter cada vez mais rígido e legalista, enquadrando-se mais em um perfil de controle e de não distribuição de bens e recursos sociais: "Trabalho social e trabalho policial obedecem assim a uma mesma lógica de controle e 
reeducação das condutas dos membros fracos ou incompetentes da classe trabalhadora" (2001: 47).

De acordo com os princípios arrolados por Wacquant (2001), a autonomia juvenil e a sua transição para a vida adulta, vivenciadas por aqueles provenientes de grupos populares urbanos, fechavam-se na perda da assistência até então recebida, assim como na aproximação com o universo judiciário dos presídios, reafirmando sua origem de vida e perspectivas possíveis para a vivência da vida adulta, ou seja, de sua autonomia.

Esses elementos configuram-se como sendo de extrema relevância, e com impactos significativos no sofrimento social vivenciado, assinalando a vida daqueles meninos e meninas e perpassando a discussão acerca da delimitação sociocultural e contemporânea sobre a passagem para a vida adulta e a vivência autônoma de projetos de vida. A delimitação sobre a autonomia sobre si e os caminhos possíveis de trilhar são elementos de difícil debate acerca das juventudes, especialmente daquelas em situações socioeconômicas desfavoráveis.

Numa arena híbrida, influenciada por fatores de diferentes ordens, o papel das ações sociais desempenhadas junto a essa população pode reforçar ou combater os aspectos da autonomia ou da tutela, na dimensão de acesso aos direitos sociais, implicando em consequências que traçam cursos diversos de vida.

\section{LUCAS: ENTRE A TUTELA DIFERENCIADA E A PROMOÇÃO DA AUTONOMIA POSSÍVEL}

Para ilustrar este debate sobre o acesso aos direitos sociais, o papel das políticas, dos serviços e da sua intermediação entre a tutela e a construção da autonomia da população atendida, relataremos o caso de Lucas, a partir da ótica dos serviços que o acompanharam, juntamente com alguns relatos seus, buscando dar luz às contradições criadas no processo e na dinâmica vivenciados, e ao sofrimento social produzido. ${ }^{3}$

A história de vida de Lucas era pouco conhecida pelos técnicos da rede de serviços, quanto à sua vinculação familiar, ao momento e motivos para a sua saída para as ruas. Ele não falava muito sobre esse tema, dizia: "O meu passado é uma coisa que eu não gosto muito de mexer, porque é uma coisa que, para mim, dói, por tudo que eu passei”. Havia algumas informações em seus prontuários, provenientes dos serviços que tinha frequentado em seu bairro.

Lucas se iniciou na rede de instituições sociais com quase 17 anos, tendo sido encaminhado por uma instituição para participação em um grupo de

3 Assinala-se que o relato apresentado tem a finalidade de discutir as ações implementadas para a intervenção social, sob o questionamento da produção de autonomia e de tutela. Assim, pouco se lança mão de relatos específicos do jovem, priorizando sua trajetória pelos serviços sociais. 
Narcóticos Anônimos (NA). ${ }^{4}$ Desde então, essa experiência o acompanhou em sua trajetória institucional e também em seu discurso verbal sobre a vida nas ruas e o uso de drogas, sempre enfatizando em seus relatos a opção consciente de cada um para o uso e a necessidade de um desejo individual para a saída dele, conforme os preceitos ensinados pelos NA. Após três meses internado na comunidade terapêutica, foi encaminhado para um abrigo e transferido, posteriormente, para outras instituições.

Nessas passagens pelos serviços de moradia, foi levado à unidade de saúde para ser inserido nas atividades locais, com uma queixa, por parte dos técnicos, de um perfil "de crises de violência", momentos nos quais diziam que ele não controlava seus atos e colocava em risco a si mesmo e a outros, pela força física de que dispunha, oriunda de sua estrutura corpórea. Por causa desses argumentos, o serviço de saúde administrou medicação psiquiátrica, por um período de quatro meses, para o auxílio na contenção desses "sintomas".

A necessidade de um local para viver era fortemente manifestada na história de Lucas em todo o período de sua passagem pela rede de serviços sociais. Argumentava enfaticamente sobre a impossibilidade de retorno para a casa de sua família. Esse fato, vinculado à sua idade, próxima aos 18 anos, acarretava o questionamento sobre qual seria a possibilidade de sua inserção social, sua manutenção financeira independente e o espaço físico concreto que ele poderia ocupar para "morar".

Os abrigos são opções provisórias de moradia, que não respondem à questão sobre a continuidade de um local para viver, para aqueles que não têm a possibilidade de retorno para as suas famílias. Explicita-se uma situação eminente e concreta: como solicitar a vivência da autonomia da fase adulta sem poder contar com um espaço físico de moradia?

Coloca-se a discussão em torno da proteção, proporcionada pela tutela, da liberdade e da autonomia de decisão sobre si. Conforme apresentado, a ideia de tutela das crianças e dos adolescentes, no âmbito da sociedade brasileira, associa-se à proteção a ser oferecida pelo Estado, pela sociedade e pela família. Trata-se da busca de acesso aos bens sociais, visando aos direitos constitucionais. Entretanto, olhando para os cenários reais da vida cotidiana, tais direitos são pouco acessíveis, na medida em que o padrão de desigualdade econômica está estabelecido, esvaziando os sentidos teóricos para a proteção e a tutela.

Daí o debate diversifica-se em torno da questão de quem tem e pode ter autonomia de decisão sobre si. O conceito de autonomia, classicamente

4 Os Narcóticos Anônimos caracterizam-se como um grupo de autoajuda para enfrentamento do uso de drogas, com base na doutrinação religiosa, abstinência e auxílio dos pares. Para uma discussão aprofundada, a partir de uma abordagem antropológica sobre grupos de autoajuda, ver Fainzang (2007). 
apresentado por Kant (1960), descreve a capacidade da vontade humana para se autodeterminar, segundo a moral estabelecida e pelo sujeito aceita, efetivada num processo reflexivo. Portanto, a autonomia não se dá numa produção "natural", mas sim na elaboração sociocultural individual e coletiva dos sujeitos. Nessa direção, Sennett (2004), a partir de Winnicott, aponta como necessária, para a construção da autonomia, a aceitação no outro daquilo que não compreendemos, e destaca que conferir autonomia ao outro significa supor sua participação nas condições de sua própria vida.

Assim, fica a questão de qual é a autonomia que pode ser estabelecida na realidade dos jovens pobres e qual a tutela que se faz necessária para que consigam, efetivamente, construir, com liberdade, suas vidas. A temática é pouco explorada e requer que seja ultrapassado o imaginário social existente sobre o jovem pobre, para que sejam verdadeiramente discutidas as necessidades de proteção e as possibilidades de autonomia.

$\mathrm{Na}$ realidade que estudamos, fazer 18 anos, ou seja, passar a fronteira da maioridade, significava perder algum nível de proteção e negociação e ser totalmente responsável por si. Como consequência, era comum, nos relatos dos profissionais, a percepção da maior adesão dos jovens, nessa fase, aos serviços. A baixa adesão dos jovens às proposições institucionais é um tema recorrente no discurso dos atores institucionais, nos apontamentos acerca do acúmulo de uma maioria de não adesão. Assim, aqueles que "aderem" às proposições e aos encaminhamentos, incorporando-se aos códigos locais, acessam ganhos secundários (Goffman 1974) no universo institucional, ou seja, para eles são ofertados alguns benefícios diferenciados, que não chegam para "todos", e, assim, podem desfrutar de circulação, acesso e oportunidades distintos. Esse era o caso de Lucas, que, desde sua entrada na rede de serviços, foi progressivamente realizando as atividades e encaminhamentos, conforme lhe eram propostos, e assim acessava outras atividades e outros lugares sociais ofertados pelos profissionais de diferentes equipamentos que frequentava.

Lucas permanecia de forma contínua nos serviços, com alguns comportamentos considerados inadequados, comumente brigas e agressões físicas. Aderiu, também, aos acompanhamentos médico-psiquiátrico e psicológico propostos pelo serviço de saúde, havendo uma diminuição de suas "crises de violência", características de sua chegada à rede. Pôde, posteriormente, interromper o uso da medicação. Ele demonstrava também interesse pela realização de cursos de informática e, por isso, foi convidado a monitorar a sala de computadores de uma das instituições, ficando nas máquinas por um tempo superior aos demais usuários, que só poderiam acessá-las acompanhados de funcionários e por um período limitado. São estes exemplos de situações nas quais ele ocupava lugares diferenciados e ganhava a confiança dos profissionais, fato que ele percebia e claramente mencionava: 
“Todo mundo me conhece, como eu era no começo, que eu não tava nem aí pra nada, não queria saber de nada, e depois eu fui mudando de comportamento, fui evoluindo. Comecei a fazer a oficina de informática aqui dentro e depois eu peguei uma confiança que nem eu pensei que ia pegar, com o pessoal aqui, que é uma coisa que dura até hoje. Me chamam para fazer as coisas, para ter participação nas coisas importantes e isso me deixa muito feliz, porque essa confiança era uma coisa que há muito tempo eu não tinha. As pessoas confiam de eu poder entrar numa sala sozinho sem ninguém estar vigiando, a bolsa do pessoal poder ficar nos lugares, sem ninguém desconfiar que eu vou pegar. Então é isso!” [Lucas]

Lucas enfatizou, em seu discurso, um elemento relevante e perceptível na vivência desses meninos: a falta de confiança neles como sujeitos. Sua menção e percepção sobre "entrar nos locais sem ser vigiado" e "as pessoas confiarem que não corriam riscos com a sua presença" demonstra, claramente, o lugar social ocupado pelos jovens de grupos populares. Essa juventude, no imaginário social, transita entre uma invisibilidade e uma visibilidade pela periculosidade, sendo submetida, cotidianamente, a processos objetivos e subjetivos de humilhação social (Soares, MV Bill e Athayde 2005) que causam sofrimentos sociais.

Dentro do universo institucional dessa rede de serviços, Lucas superou essa posição e passou a ser um ombro de apoio para o funcionamento local, uma via de acesso ao mundo da rua, uma figura positiva para a apresentação do trabalho desempenhado pelos equipamentos sociais. Estabeleceu-se, então, uma "troca" na qual foi ofertada uma posição diferenciada para Lucas, como usuário da rede de serviços, com acessos e posicionamento especiais, nos campos objetivos e subjetivos; e foi solicitada sua representação e relato, para o contexto externo, do trabalho desenvolvido pelos mesmos serviços. Lucas passou a ser convidado para participar dos fóruns coletivos da cidade como representante dos usuários dos serviços para meninos e meninas em situação de rua e, assim, foi inscrito e, efetivamente, participou de conferências, seminários, debates e eventos sobre a infância e juventude, naqueles em que estava previsto assento para os usuários. Com essa prática, ganhou um linguajar próprio desse meio, apreendeu situações e processos de decisão, e incluiu, na sua fala, a temática dos direitos e do protagonismo. ${ }^{5}$

“É importante participar, porque um adolescente entrando numa palestra é protagonista, montando o que ele tem para falar, ele acaba adquirindo

5 O termo "protagonista" foi difundido e divulgado no final da década de 1990 relacionado à educação não formal e às ações realizadas por jovens, podendo ser, ou não, mediada por adultos. Refere-se à horizontalidade das ações e à assunção de ações e projetos sociais desenvolvidos no âmbito escolar e/ou comunitário pelos próprios jovens (Borba 2007). Acumula, também, muita crítica frente ao uso indistinto do termo e a uma perspectiva "salvacionista" das ações da juventude. 
mais responsabilidade, acaba conhecendo coisas novas, pessoas, outros tipos de pessoas, aprende a conviver com a sociedade. Porque um seminário é mais ou menos a sociedade, tem o prefeito, aparece o prefeito, aparece assistente social, aparece pedagoga, enfim, aparece todo tipo de pessoa. E eu acho, também, que o adolescente ser protagonista é uma coisa muito importante, porque é difícil para o adolescente poder expor suas ideias. Isso é uma coisa que antigamente não acontecia, de adolescente ir em seminários, fazer apresentação e realmente falar o que ele pensa e as pessoas ouvindo, entrar para uma mesa de debate. Eu acho que é, nossa, superinteressante! Principalmente pra mim, pra mim é interessante porque é uma coisa que eu gosto de fazer. Que é conhecer os direitos e estar cobrando aquilo que por direito é meu. Eu, então, gosto muito de mexer com isso, de dar palestra, de ouvir os caras falando, de poder discordar ou concordar" [Lucas].

Lucas também se inseriu na rede formal de ensino. Frequentou-a pelo período de um ano. Dispunha de um histórico no ambiente escolar mais longo do que o da maioria dos adolescentes de sua idade e condição social e, embora tivesse sido expulso da escola de seu bairro, ao contrário da realidade presente do universo onde estava inserido, tinha um grau de conhecimento escolar diferenciado. Com essa avaliação, foi matriculado diretamente no ensino médio. Teve problemas "de comportamento" na escola em que estava, o qual, segundo seu relato, era resultado de suas atitudes críticas e contestadoras da metodologia pedagógica empregada pela professora local. Foi, então, transferido para outra escola a fim de dar continuidade aos estudos.

Lucas vislumbrava a escolarização como possibilidade de mudança de seu lugar social e abertura de horizontes para alcançar outro patamar, que poderia ser acessível a partir de uma formação universitária. Por essa trajetória, via a possibilidade de tecer sonhos e outros trajetos.

"Minha vida daqui pra a frente é continuar, eu já tô quase para completar 18 anos, né? Eu acho que é pegar firme nos estudos, fazer os cursos profissionalizantes na área de informática, que é o que eu gosto, e se pá, fazer assistência social, que é uma coisa que eu curto bastante também. Fazer uma faculdade de direito, não sei, porque eu tenho várias coisas em mente, de faculdade para eu fazer, e eu acho que, daqui para frente, também, continuar os projetos que eu tô começando agora, por exemplo, dar aula de informática no CRAISA, que é uma coisa nova, nunca pensei que eu ia dar aula. E acho que é isso. E continuar correndo atrás do que eu quero, atrás dos meus sonhos" [Lucas]. ${ }^{6}$ 
Para Lucas, a entrada na rede de serviços, e sua adesão a ela, foi a possibilidade de trilhar seu percurso, aproveitar benefícios que passou a acessar e criar novos posicionamentos e funções sociais advindos desse processo. Com isso, o futuro, e sua visualização, alcançou o discurso, os planos, os sonhos.

Após completar 18 anos, pelo seu "bom" comportamento, Lucas começou a trabalhar em dois projetos sociais, passando, em um deles, da condição de usuário para educador. Compôs a equipe, em uma organização não governamental, de ações com meninos e meninas em situação de rua. No outro local, estava ligado a um projeto de democratização do acesso à informática, com financiamento público, no qual ministrava aulas de computação.

Com isso, foi possível o pagamento próprio de sua moradia. Morava com um outro colega, com quem dividia as despesas de uma casa simples. Persistia desenvolvendo o papel de representação política, por meio da participação ativa nos eventos na área da infância e da juventude.

Sua autonomia foi viabilizada pela sua inserção no trabalho, por meio dos serviços de que participou na condição de usuário, onde recebeu importantes pontos de suporte pessoal e social, traduzindo-se em um amplo fortalecimento de sua sociabilidade primária e potencialidades perante a vida.

É evidente o significado do trabalho remunerado na vida de Lucas e, a partir dele, a possibilidade de ascender a um novo papel social, com sua maioridade e inserção do outro lado da rede, na condição de trabalhador. Juntamente com isso, continuou a contar com seu lugar "diferenciado", entre muitos técnicos, e apoios contínuos que certamente embasaram e favoreceram seu percurso.

No entanto, essa realidade não é oferecida para a maioria dos jovens ex-usuários dos serviços para crianças e adolescentes; para muitos, a "corda bamba" da sobrevivência e as condições de pobreza permaneceram como elementos centrais de sua trajetória e são "passadas" de geração para geração, impressas nas histórias de pais, filhos e, talvez, dos filhos desses jovens.

Lucas seguiu as proposições a ele sugeridas, tendo deflagrado poucos momentos de tensão e contestação. Pelos agenciamentos próprios que realizou, conquistou entre os técnicos uma permissividade e ganhos efetivos que modificaram sua trajetória. Assim se compõem os momentos de "não adesões", pelo seu histórico, desde sua entrada na rede, junto aos de cooperação e de enquadramento nos diversos encaminhamentos dos serviços. Com isso, seguiu para um lugar diferenciado nesse contexto e verbalizava seus ganhos diretos e secundários conquistados, a partir de sua adaptação à rede, às instituições e aos trabalhadores.

Os ganhos obtidos por ele são nítidos e exemplificam uma mudança do lugar social ocupado como usuário da rede de serviços, expressa diretamente na oferta da participação e representação em seminários, conferências e outros coletivos, para os quais os usuários dos serviços normalmente não são 
convidados, assim como na possibilidade de utilização de recursos locais, de difícil acesso e interesse dos meninos. Obteve também ganhos indiretos, exemplificados quando relatou a autorização recebida para circulação por "espaços exclusivos dos funcionários" no ambiente institucional e a não mudança de comportamento por parte dos técnicos locais com a sua presença.

Esses benefícios possibilitaram sonhos de futuro para Lucas e a mobilização dos agentes institucionais para viabilizá-los. O fato é de extrema relevância e importância para o processo de trabalho de todos os serviços da rede. Não obstante, consideramos que não haveria espaço para todos, nesse mesmo grau de atenção e proteção, caso houvesse maior disponibilidade para essa "adesão" por parte dos jovens, ou para agenciamentos próprios que visualizassem esse caminho. Essa história representa uma concretização da possibilidade efetiva de ganhos diretos e secundários, mas eles são conquistados mais pela lacuna existente dos poucos que aderem aos serviços, do que pela oferta universal para aquele público. Os fatores que levaram Lucas a ocupar esse lugar, diferenciando-o na aceitação das proposições que lhe foram dirigidas, podem ser de diversa natureza, pessoal e institucional; contudo, sua situação e trajetória, influenciadas pelos serviços e profissionais que com ele trabalharam, parecem ser possíveis apenas na atual estrutura de escassas adesões contínuas por parte dos usuários.

\section{CONSIDERAÇÕES FINAIS}

A trajetória de Lucas demonstra sua inserção autônoma na vida como um jovem adulto, alguém que pôde viabilizar economicamente um lugar para morar e reunir recursos para a sobrevivência por meio do trabalho, com sonhos que apontam em seu horizonte como possibilidades para a sua vida.

Entretanto, a positividade de sua passagem pelos 18 anos apresentou-se, em nossa experiência de terreno, como uma exceção, na medida em que a maior parte daqueles meninos e meninas vivia a entrada na vida adulta como uma amplificação de seu sofrimento social, o agravamento das condições efetivas de vida e o ingresso maciço no universo prisional do mundo adulto.

Assim, optamos pelo relato dessa história para, na contemplação dos ganhos efetivos naquela trajetória, apresentar a fragilidade de acolhimento do sofrimento social, mesmo num contexto jurídico de valorização da infância e da juventude, como no Brasil, junto ao elogiado referencial do Estatuto da Criança e do Adolescente (ECA).

É preciso ampliar a discussão acerca das efetivas possibilidades dos serviços sociais voltados aos jovens e analisar o que tem se produzido por meio da tutela dessa população, bem como quais os resultados alcançados para a promoção de sua autonomia e exercício reflexivo para sua autodeterminação, nos percursos criativos pessoais de cada jovem. 
Não obstante, faz-se necessário afirmar que é ainda por meio das ações sociais que se garante algum nível de proteção e horizonte de acesso aos direitos para as crianças, adolescentes e jovens brasileiros. Colocar o foco em elementos como aqueles trazidos pela história de Lucas objetiva as dinâmicas em curso, tendo em vista o conhecimento e a reflexão aprofundados sobre elas, o aprimoramento da ação voltada para suas potencialidades, para a criação de espaços que culminem em intervenções que venham a facilitar o acesso aos direitos por parte daquela população, afastando-se de discursos que não se viabilizam enquanto proposição, na medida em que envolvem uma gama de questões para além daquelas superficialmente estabelecidas.

Portanto, discutir as ações institucionais de promoção da tutela com vistas à autonomia de grupos juvenis requer a consideração conjunta de aspectos econômicos, de criação de trabalho e emprego, a par dos limites colocados pelas desigualdades sociais vivenciadas, numa perspectiva que suplanta a visão homogênea da juventude como "problema político".

Para que as ações públicas ajam na sua potencialidade é preciso que abandonem o paradigma do jovem como "problema", referindo-se especificamente àqueles advindos de segmentos populares, e instituam esforços para a ressignificação dos objetivos institucionais em uma perspectiva direcionada à vertente emancipatória e autônoma.

Nossa demarcação nos grupos populares visa ao aprofundamento e à compreensão dos tipos de respostas que vêm sendo produzidas no cotidiano das políticas sociais, que são de natureza focal. Voltar-se a esse recorte da população tem o intuito de dar visibilidade àqueles que menos ocupam o lugar de protagonistas e de debater processos e ações que realizem, ou possam vir a realizar, a promoção de direitos e de condições menos injustas e mais solidárias de vida, em resposta ao sofrimento social vivenciado em função da condição em que se encontram. Assim, trabalhamos pela circulação de projetos e ideias que assumam o desafio da tentativa de promover a igualdade de oportunidades, em uma estrutura previamente desigual e de precariedades.

Portanto, é preciso pautar o debate sobre a vivência do sofrimento social por jovens de grupos populares, a especificidade da passagem para a vida adulta, e o evento crítico aí estabelecido, para, então, se discutir as possibilidades e limites das ações institucionais em torno da autonomia dessa população. 


\section{BIBLIOGRAFIA}

ABAD, Miguel, 2003, "Crítica política das políticas de juventude", em Maria Virgínia de Freitas e Fernanda de Carvalho Papa (orgs.), Políticas Públicas: Juventude em Pauta. São Paulo, Cortez, Ação Educativa, Fundação Friedrich Ebert, 13-32.

ABRAMO, Helena W., e Oscar Dávila LEÓN, 2005, Juventude e Adolescência no Brasil: Referências Conceituais. São Paulo, Ação Educativa.

ADORnO, Rubens de Camargo Ferreira, Augusta T. AlvarengA, e Maria da Penha C. VASCONCELLOS, 2005, "Jovens, gênero e sexualidade: relações em questão para o campo da saúde pública", em Rubens de Camargo Ferreira Adorno, Augusta T. Alvarenga e Maria da Penha C. Vasconcellos (orgs.), Jovens, Trajetórias, Masculinidades e Direitos. São Paulo, Fapesp, Editora da Universidade de São Paulo, 16-29.

ATTIAS-DONFUT, Claudine, 1996, "Jeunesse et conjugaison des temps", Sociologie et Sociétés, 28 (1): 13-22.

BIEHL, João, 2008, "Antropologia do devir: psicofármacos - abandono social - desejo", Revista de Antropologia, 51 (2): 413-449.

BORBA, Patrícia Leme de Oliveira, 2007, "Protagonismo", em Margareth Brandini Park, Renata S. Fernandes e Amarildo Carnicel (orgs.), Palavras-Chave na Educação Não-Formal. Holambra, Editora Setembro; Campinas, Unicamp, Centro de Memória da Unicamp (CMU), 241-242.

BOURDIEU, Pierre, 1986, "De quoi parle-t-on quand on parle du "problème de la jeunesse'?”, em François Proust (org.), Les jeunes et les autres: contributions des sciences de l'homme à la question des jeunes. Vaucresson, CRIV, 229-235.

BRASIL, 1988, Constituição da República Federativa do Brasil. Brasília, Centro Gráfico.

— 1990, Estatuto da Criança e do Adolescente. São Paulo, Cortez.

CASTEL, Robert, 1998, As Metamorfoses da Questão Social. Petrópolis, Vozes.

DEBERT, Guita Grin, 2010, "A dissolução da vida adulta e a juventude como valor", Horizontes Antropológicos, 16 (34): 49-70.

DUBET, François, 1987, La galère: jeunes en survie. Paris, Librarie Arthème Fayard.

FAINZANG, Sylvie, 2007, Curar-se do Álcool: Antropologia de Uma Luta contra o Alcoolismo. Niteroi, Intertexto.

FEATHERSTONE, Michelle, 1994, "O curso da vida: corpo, cultura e o imaginário no processo de envelhecimento”, em Guita Grin Debert (org.), Antropologia e Velhice. Campinas, IFCH, Unicamp, 49-71.

FONSECA, Cláudia, e Andrea CARDARELLO, 1999, "Direitos dos mais e menos humanos", Horizontes Antropológicos, 5 (10): 83-121.

FRÚGOLI JÚNIOR, Heitor, 2007, Sociabilidade Urbana. Rio de Janeiro, Jorge Zahar.

GOFFMAN, Erving, 1974, Manicômios, Prisões e Conventos. São Paulo, Perspectiva.

IARD, 2001, Étude sur la condition des jeunes et sur la politique pour la jeunesse en Europe: Résumé éxécutif. Milão, IARD, Instituto Associato Assirm (Associazione tra Instituti di Ricerche di Mercato).

KANT, Immanuel, 1960, Fundamentação Metafísica dos Costumes. Lisboa, Edições 70.

KLEINMAN, Arthur, Veena DAS, e Margareth LOCK (orgs.), 1997, Social Suffering. Berkeley, Los Angeles e Londres, University of California Press.

LONCLE, Patrícia, 2003, L'action publique malgré les jeunes: les politiques de jeunesse en France de 1870 a 2000. Paris, L'Harmattan. 
NOVAES, Regina, et al. (orgs.), 2006, Política Nacional de Juventude: Diretrizes e Perspectivas.

São Paulo, Conselho Nacional de Juventude, Fundação Friedrich Ebert.

PAIS, José Machado, 2005, Ganchos, Tachos e Biscates: Jovens, Trabalho e Futuro. Porto, Âmbar, Enciclopédia Moderna de Sociologia, vol. 3.

PAUlA, Paulo Afonso Garrido, 2010, "Criança, adolescente e jovem”, Revista Brasileira Adolescência e Conflitualidade, 3: 1-3.

RIZZINI, Irene, 2008, O Século Perdido: Raízes Históricas das Políticas Públicas para a Infância no Brasil. São Paulo, Cortez, 2. ${ }^{\text {a }}$ ed. revista.

SENNETT, Richard, 2004, Respeito: A Formação de um Caráter em um Mundo Desigual. Rio de Janeiro, Record.

SOARES, Luiz Eduardo, MV BILl, e Celso ATHAYDE, 2005, Cabeça de Porco. Rio de Janeiro, Objetiva.

SPOSITO, Marília Pontes, 2007, "Introdução: espaços públicos e tempos juvenis", em Marília Pontes Sposito (org.), Espaços Públicos e Tempos Juvenis: Um Estudo de Ações do Poder Público em Cidades de Regiões Metropolitanas Brasileiras. São Paulo, Global, 5-43.

SPOSITO, Marília Pontes, e Paulo César Rodrigues CARRANO, 2003, "Juventude e políticas públicas no Brasil”, Revista Brasileira de Educação, 24: 16-39.

WACQUANT, Loïc, 2001, As Prisões da Miséria. Rio de Janeiro, Jorge Zahar.

Contemporaneity and youth: between autonomy and protection - Ana Paula Serrata Malfitano - Departamento de Terapia Ocupacional, Programa de Pós-Graduação em Terapia Ocupacional, Universidade Federal de São Carlos, Brasil • anamalfitano@ufscar.br

Youth, characterized as a plural and emerging social group, has been increasingly present in public debates and actions globally. However, young people from popular classes are predominantly being regarded though a homogenising perspective as a "political problem", leading to the development of disciplinary intervention and control. Such interventions struggle with the legal, cultural and social constitution of youth, questioning who should be the youngsters under protection and guardianship, and which ones should have the freedom and autonomy to decide about their lives. Social services targeted to this population do intend to promote their autonomy. Based on ethnographic work, done for four years with social institutions and young people who attended them, the article presents the life story of a young man on the threshold to adult life, understanding the passage to adulthood as a critical event of social suffering. We emphasize the access gained, in his itinerary, to social and economic autonomy, but this case is presented as an exception, given the actual narrow effects of the actions of social services regarding young people of lower-class groups.

KEYWORDS: youth, autonomy, guardianship, social institutions. 